\title{
Collagen Fibrillar Skeleton in Pregnant Rabbit Endo- metrium at Term: A SEM Study after NaOH Maceration*
}

\author{
Vania Goranova ${ }^{1}$, Enrico Vizza ${ }^{2}$, Silvia CoRren ${ }^{2}$, Rosemarie Heyn ${ }^{3}$ and Pietro M. MotTa ${ }^{2}$ \\ Department of Anatomy and Histology ${ }^{1}$, University of Varna Medical School, Varna, Bulgaria; Department of Anatomy ${ }^{2}$, \\ University of Rome "La Sapienza" Medical School, Rome, Italy; and Department of Experimental Morphology ${ }^{3}$, University \\ of Chile, Santiago, Chile
}

Received November 24, 1995

\begin{abstract}
Summary. This paper describes the spatial organization of the collagen fibrillar skeleton in pregnant rabbit endometrium at term, employing an alkali/low temperature/maceration technique followed by scanning electron microscopic (SEM) observations. Parallel light microscopic (LM) and transmission electron microscopic (TEM) investigations were made to identify the location and possible changes in the endometrial collagen network. Two different types of $\mathrm{NaOH}$ maceration were applied, demonstrating separately: 1) the collagen structures $(2 \mathrm{~N}-\mathrm{NaOH}$ maceration removes the cells and basal laminae); and 2) the cellular elements $(6 \mathrm{~N}-\mathrm{NaOH}$ maceration removes the collagen fibrils).

After $2 \mathrm{~N}-\mathrm{NaOH}$ maceration, the collagen network of the endometrium is seen in a superficial compartment around the glands and a deep compartment situated near the endometrial-myometrial junction. Significant changes are observed only in the superficial compartment. The luminal mucosal surface is characterized by numerous thin projections reducing the uterine cavity which, as a consequence, further appears very irregular and highly convoluted. The subepithelial collagen network is composed of densely packed fibrils with a woven course. It contains many tubular or channel-like invaginations $(100-150 \mu \mathrm{m}$ in width and $200-300 \mu \mathrm{m}$ in length) where endometrial glands are located. These invaginations, corresponding to the glandular impressions, are extremely dilated, enlarged and variable in shape. The collagen fibrils are arranged concentrically around the glandular orifices without forming bundles. At the bottom of the spaces between the mucosal projections, small fenestrations (4-8 $\mu \mathrm{m}$ in diameter each) are present. They form small groups of about 10-20 in number and are due to the endometrial blood capillaries. The deep compartment of the endometrial collagen network is little altered, preserving its general lamellar arrangement.
\end{abstract}

The changes in the endometrial collagen skeleton are due to a variety of complex mechanical and hormonal stimuli affecting the uterus during pregnancy. These may be significant for correct implantation, placentation and delivery.

During reproductive activity, the uterus is subjected to important morphological and functional changes in response to the ovarian hormones (FEDER, 1981; LUDWIG, 1982; MARTEL et al., 1987; DOCKERY and ROGERS, 1989; KRAMER et al., 1990; AMSO et al., 1994). Many studies have shown various modifications in collagen parameters of the endometrium (concentration, distribution, histologic features) related to specific physiological and experimental states such as decidualization, pregnancy, and delivery (MARTELLO and ABRAHAMSOHN, 1986; KISALUS et al., 1987; ALBERTO-RINCON, 1989; YoshIDA and MANABE, 1990; ClARK et al., 1992). Although collagen is the main constituent of the extracellular matrix of the endometrial stroma (JEFFREY, 1991), little is known about its spatial location and three-dimensional (3-D) organization, its changes during the ovarian cycle and other functional states. This lack of information is due to technical problems, since the collagen fibrils are not accessible for direct observation by scanning electron microscopy (SEM) owing to the presence of masking amorphous ground substance and cellular elements (VIzZA et al., 1994). Recently, this problem has been solved by the introduction of a new type of alkali maceration technique at low temperature which preserves the collagen and allows the detailed study of the spatial 3-D arrangement of the collagen fibrils in different organs, includ-

*This work was supported by funds of M. U. R. S. T., Italy. 
ing the pancreas (OHTANI, 1987), liver (OHTANI, 1988, 1992), cardiac muscle, tongue and small intestine (OHTANI et al., 1988), adrenal gland (KIKUTA et al., 1991) and oviduct (VIzZA et al., 1993, 1994). In a previous study using this maceration technique, we were able to fully reveal the fine 3-D structure of the collagen fibrillar skeleton of rabbit uterus at estrous and after stimulation with hCG (GORANOva et al., 1993a, b).

The crucial role of the uterine collagen during pregnancy and delivery is widely acknowledged

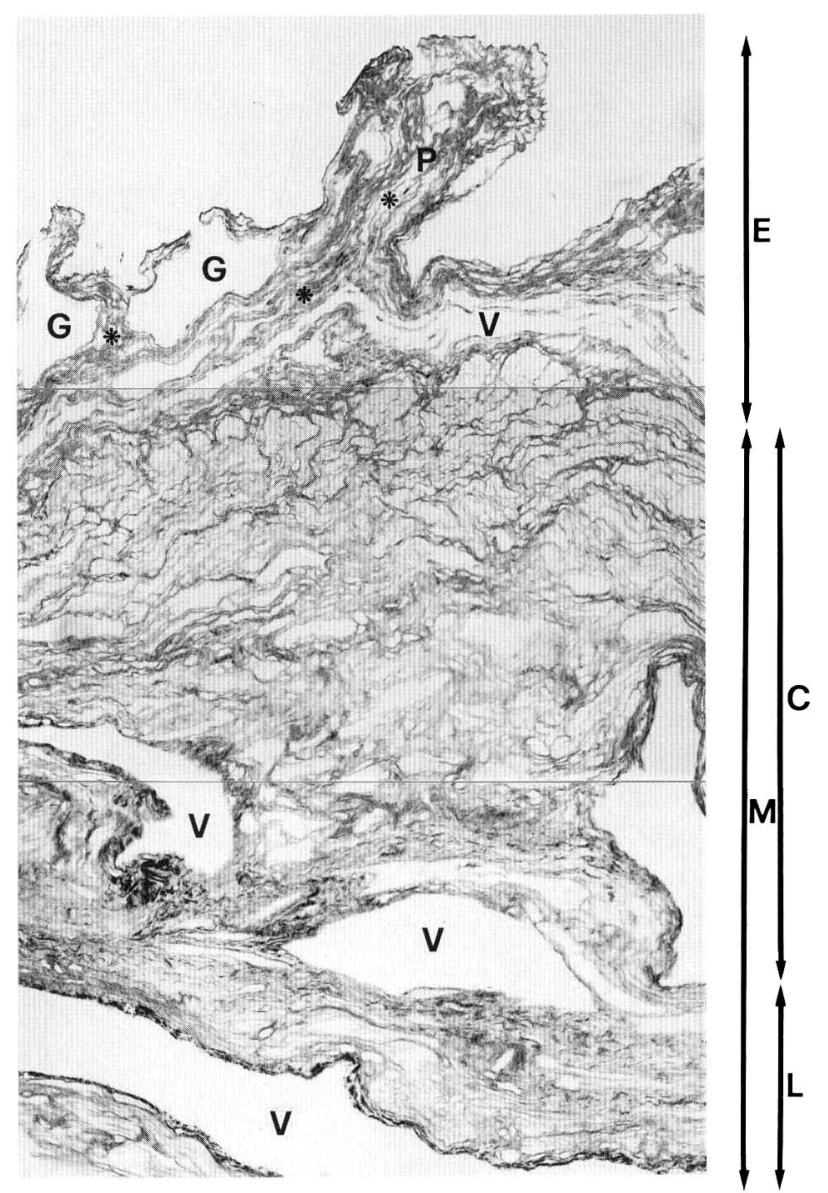

Fig. 1. Light micrograph of the collagen skeleton of pregnant rabbit uterus in an unstained semithin section after $2 \mathrm{~N}-\mathrm{NaOH}$ maceration. Elongated luminal projections $(P)$ are present in the endometrium $(E)$. They surround glandular hollow spaces $(G)$ with a diameter of 100-200 $\mu \mathrm{m}$. The superficial compartment consists of collagen fibers without a specific orientation. The deep compartment (asterisks) contains many parallel lamellae connected with the collagen network of the circular $(C)$ and longitudinal $(L)$ layers of the myometrium $(M)$. Blood vessel spaces $(V)$ are also present within the collagen skeleton. $\times 850$
(BoREL, 1991). The structural and functional alterations of the various types of uterine collagens are of paramount interest during this period of reproductive life (Uldbjerg et al., 1983; Minamoto et al., 1987; KAIDI et al., 1991). For example, it has been shown by immunohistochemical analysis that some collagen types are significantly reduced or lost during decidualization (Mulholland et al., 1992), embryo implantation (CLARK et al., 1993) and early pregnancy (MYlonA et al., 1995). Combining SEM with the new technique of cellular maceration with $2 \mathrm{~N}-\mathrm{NaOH}$ allowed us to demonstrate that: 1) the collagen fibrils form a well defined skeleton in the endometrium and constitute a specifically arranged complex scaffold supporting the cells as well as glands and stromal vessels; 2) the architecture of this collagen framework undergoes cyclical changes according to different phases of estrous, ovulation and progestation (GoRANOva et al., 1993a, b). In the present study, 6N$\mathrm{NaOH}$ maceration was applied in order to interpret better the structural and functional significance of the collagen skeleton with regard to the cellular components.

Considering that the endometrium during pregnancy is subjected to significant hormonal and mechanical stimuli, it certainly represents a suitable model for further studying the remodeling of its collagen component. Therefore, the aim of the present study was to extend our observations of the rabbit endometrium in order to describe the 3-D architecture of its collagen skeleton in pregnancy at term. Comparing these results with previous ones in non-pregnant states may provide new insight into this important tissular component.

\section{MATERIAL AND METHODS}

Five adult New Zealand sexually mature female pregnant rabbits (age: six months; body weight: $3.5-4$ $\mathrm{kg}$; 22 days of pregnancy) were anesthetized with 100 $\mathrm{mg}$ ketamine (Ketavet) $+4 \mathrm{mg}$ xylazine (Rompum, Bayer) pro $\mathrm{kg}$ and perfused through the abdominal aorta with $2.5 \%$ glutaraldehyde in $0.1 \mathrm{M} \mathrm{PBS}$ at $\mathrm{pH}$ 7.4. Then the uteri were removed and placed for further immersion fixation in the same fixative at $4^{\circ} \mathrm{C}$ for 2 days.

Specimens were taken from interimplantation sites of the uteri. Following this, they were cut into small pieces $(5-10 \mathrm{~mm}$ long) and macerated in $2 \mathrm{~N}-\mathrm{NaOH}$ for 5-7 days at $25^{\circ} \mathrm{C}$, changing the solution daily. Then the specimens were put in distilled water, changed daily, for 5 days at the same temperature until they became pale and transparent. They were 

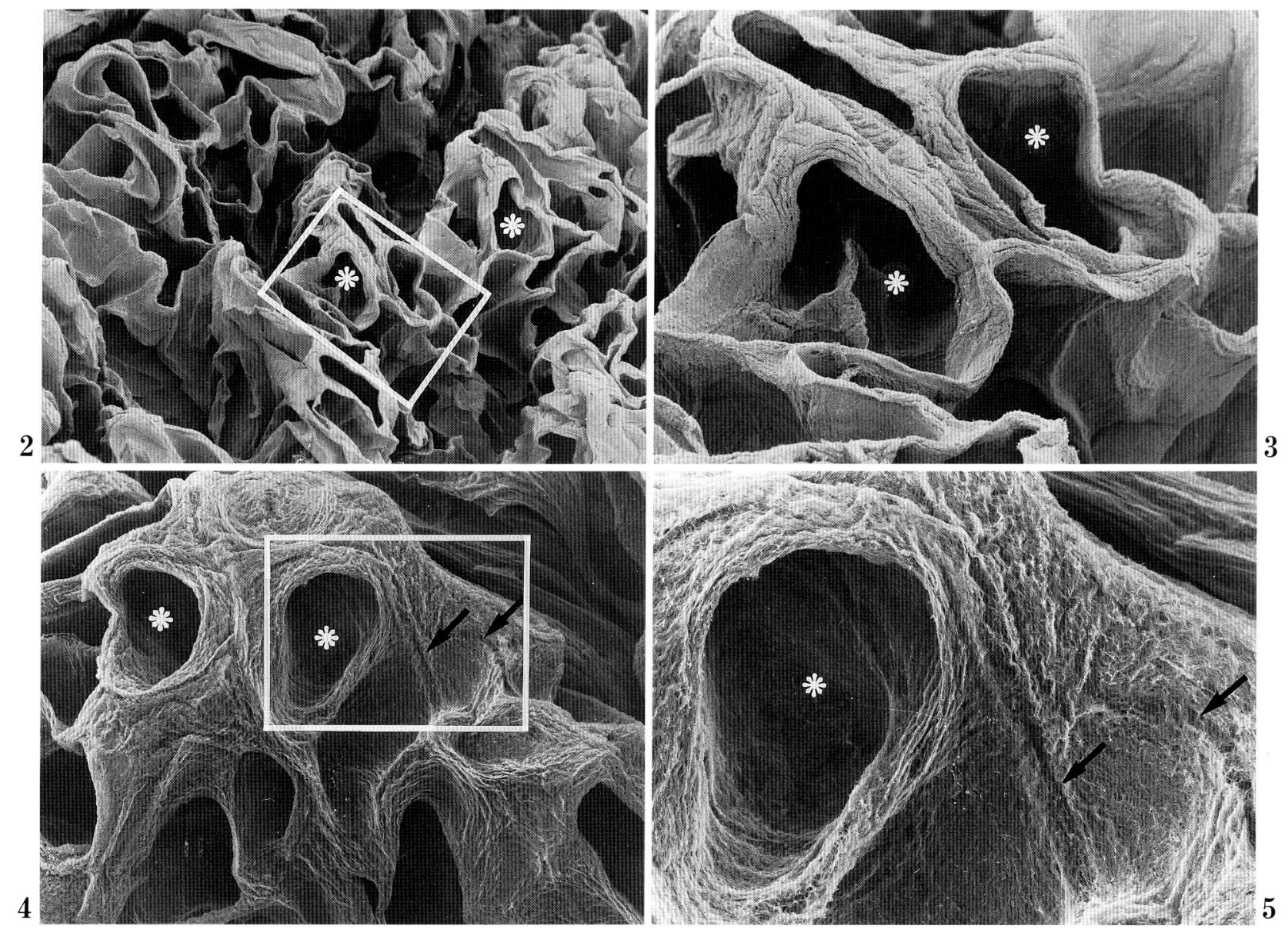

Figs. 2-5. Scanning electron micrographs (SEM) of the collagen network of pregnant rabbit endometrium at term after maceration with $2 \mathrm{~N}-\mathrm{NaOH}$. Many irregular hollow impressions corresponding to glandular sites (asterisks) are present. Fig. 2. Highly convoluted endoluminal surface. Fig. 3. Higher magnification of the area indicated in Figure 2 showing glandular openings. Fig. 4. Holes of endometrial glands surrounded by a collagen fibrillar network containing capillary imprints (arrows). Fig. 5. Higher magnification of the area indicated in Figure 4 demonstrating a concentric arrangement of collagen fibrils around a glandular orifice. Fig. 2: $\times 45$, Fig. 3: $\times 150$, Fig. $4: \times 120$, Fig. 5: $\times 300$

then immersed in $1 \%$ tannic acid aqueous solution for $3 \mathrm{~h}$. After rinsing in distilled water for $2 \mathrm{~h}$, postfixation in $1.33 \%$ aqueous solution of $\mathrm{OsO}_{4}$ was performed for $2 \mathrm{~h}$. The samples were dehydrated through a graded series of ethanol concentrations, freeze-cracked with a razor blade in liquid nitrogen and dried to critical point using liquid $\mathrm{CO}_{2}$ in a critical point dryer (Balzers CPD 020). Finally, they were mounted on specimen-holders with silver paste and coated with platinum up to a $6 \mathrm{~nm}$ thickness with a K550 sputter coater (EMITECH). Observations were made with a Hitachi S4000 field-emission SEM operating at an accelerating voltage of $5-10 \mathrm{kV}$.

Specimens from each animal were also subjected to
$6 \mathrm{~N}-\mathrm{NaOH}$ digestion for $20 \mathrm{~min}$ at $60^{\circ} \mathrm{C}$ followed by impregnation in $1 \%$ sucrose solution for $10 \mathrm{~h}$, immersion in 1\% tannic acid for $8 \mathrm{~h}$ and osmium impregnation for $6 \mathrm{~h}$ so as to preserve the cells digesting the other tissue components. Some specimens were prepared for a parallel standard SEM observation, omitting the $\mathrm{NaOH}$ maceration and tannic acid impregnation. Tissue samples (1-2 mm) were embedded in Epon resin for a correlative LM/TEM study. Semithin $(0.5-1 \mu \mathrm{m})$ and ultrathin $(70-90 \mathrm{~nm})$ sections were cut with an Ultracut microtome (Reichert). The ultrathin sections were mounted on copper grids, double stained with uranyl acetate and lead citrate and observed with a Zeiss EM10 TEM. 

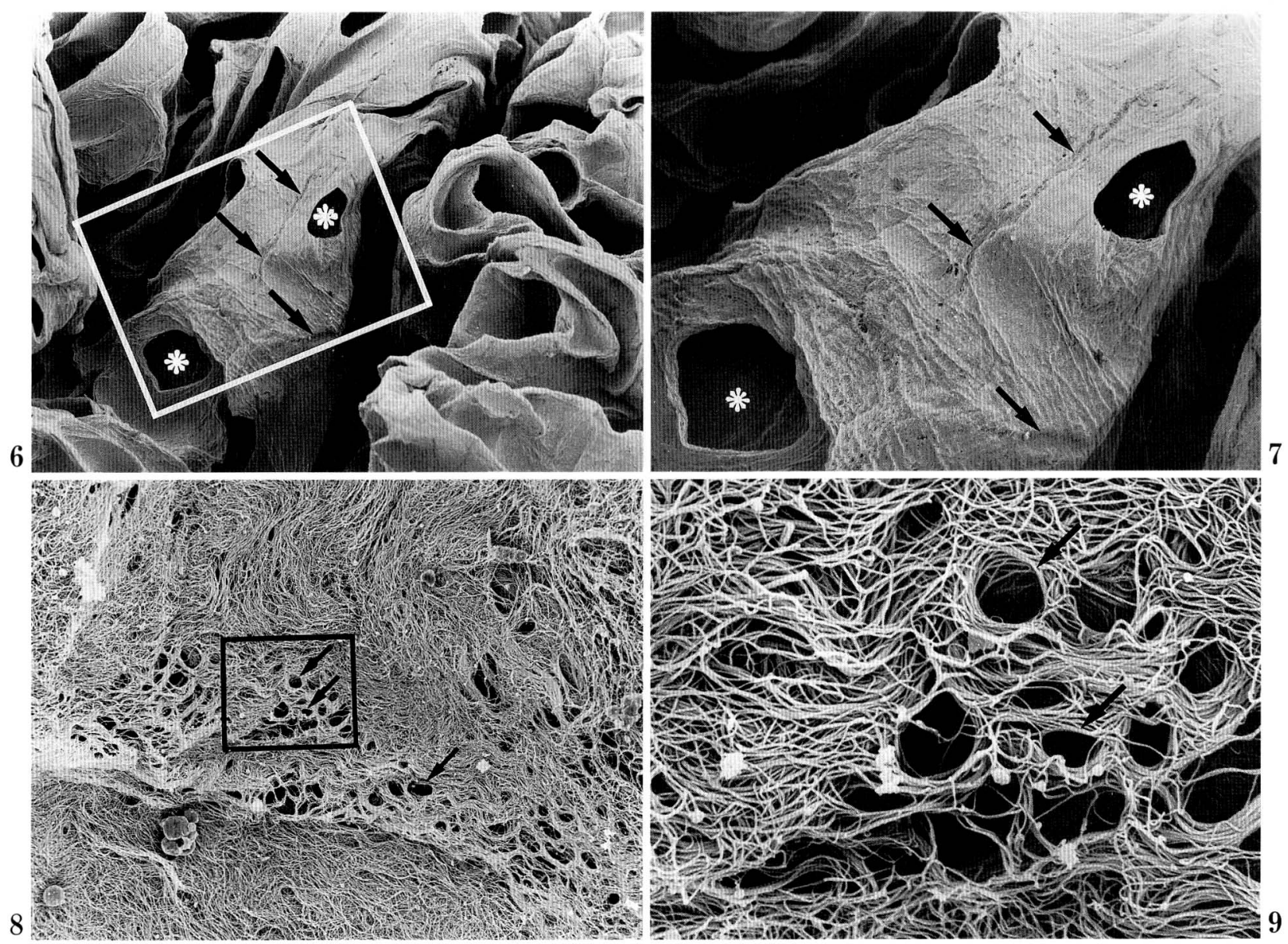

Figs. 6-9. SEM of the collagen network of pregnant rabbit endometrium at term after maceration with $2 \mathrm{~N}-\mathrm{NaOH}$, showing different compartments of the endoluminal mucosal projections. Fig. 6. Superficial part with glandular orifices (asterisks) and capillaries' imprints (arrows). Fig. 7. Higher magnification of the area indicated in Figure 6. Fig. 8. Basal part with small fenestrations $4-8 \mu \mathrm{m}$ in diameter (arrows). Fig. 9. Higher magnification of the area indicated in Figure 8. Fig. 6: $\times 70$, Fig. 7: $\times 150$, Fig. $8: \times 1,000$, Fig. 9: $\times 5,000$

\section{RESULTS}

\section{Light microscopy}

The $2 \mathrm{~N}-\mathrm{NaOH}$ maceration allows a complete removal of cells, interstitial ground substance and basal laminae without modifying the collagen architecture of the organ as demonstrated by light microscopy (Fig. 1). The collagen fibers of the endometrium form a continuous network extending into the myometrium where they display a quite different arrangement (Fig. 1). The luminal surface is characterized by numerous, elongated and extremely thin projections that reduce and make the uterine cavity irregular. They surround hollow spaces (where the endometrial glands are contained) which are very enlarged and irregular (Fig. 1).

\section{Scanning electron microscopy}

At low magnification, the luminal surface of the endometrium is highly convoluted (Fig. 2). The typical longitudinal folds that characterize the endoluminal surface at estrous are significantly reduced or even disappear. Many irregular holes representing sites of glands and their orifices are observed (Fig. 3). They are enlarged, very dilated and variable in shape, with a diameter ranging about $100-150 \mu \mathrm{m}$. At higher magnification the honeycomb appearance, typical for the endometrial collagen arrangement around the glandular openings at estrous (GORANOVA et al., 1993 

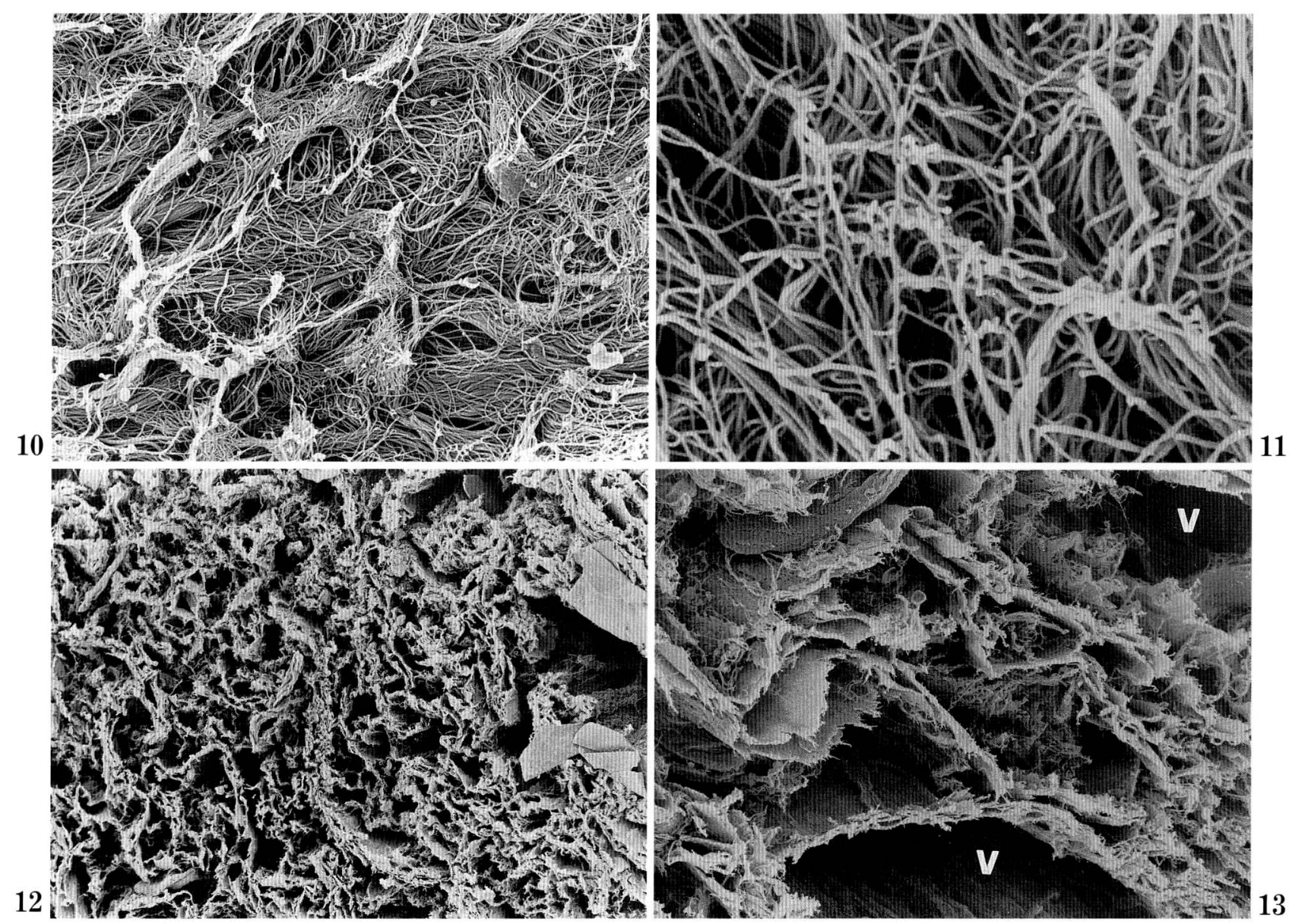

Figs. 10-13. SEM of the collagen network of pregnant rabbit endometrium at term after maceration with $2 \mathrm{~N}-\mathrm{NaOH}$. Figs. 10 and 11. Subepithelial collagen fibrils running in various directions and organized in a dense network. Figs. 12 and 13. Collagen bundles and lamellae from the basal part of the endoluminal projections (indicated by asterisks at a lower magnification in Figures 1 and 14) surrounding spaces for small blood vessels (v). Fig. 10: $\times 3,700$, Fig. 11: $\times 13,600$, Fig. 12: $\times 300$, Fig. 13: $\times 700$

b), is not present at this stage (Figs. 4, 5). Individual collagen fibrils are distributed concentrically around the glandular openings and no bundles of fibrils are found at this level (Fig. 5). At regular distances, numerous channel-like narrow imprints $(4-8 \mu \mathrm{m}$ in width) are observed (Figs. 4-7). They usually encircle glandular openings and intermingle each other in a geometrical fashion, thus forming a square-meshed network (Figs. 4, 6, 7). Very often at the bases of endometrial mucosal projections the channel-like imprints are seen to terminate with small fenestrations (4-8 $\mu \mathrm{m}$ in diameter) (Figs. 8, 9). Usually they are not isolated but tend to concentrate in small groups of about 10-20 in number (Figs. 8, 9). The subepithelial collagen network is composed of densely packed collagen fibrils with a woven course (Fig.
10). They run in every direction and intermingle with each other at random, generating a continuous network characterized by a fine reticular texture (Fig. 11).

The collagen framework of the basal portions of the endometrial projections-located near the endometrial-myometrial junction (indicated with asterisks in Figs. 1, 14) - is composed of thin bundles, lamellae and single fibrils with a woven course. They intermingle with each other to form a spongy-like skeleton containing small blood vessels (Figs. 12, 13).

Cross sections of the endometrium are easily visible on fractured samples (Fig. 14). These reveal a collagen fibrillar skeleton characterized by numerous deep, wide invaginations showing an irregular tubular or channel-like shape (Figs. 14, 15). They are 

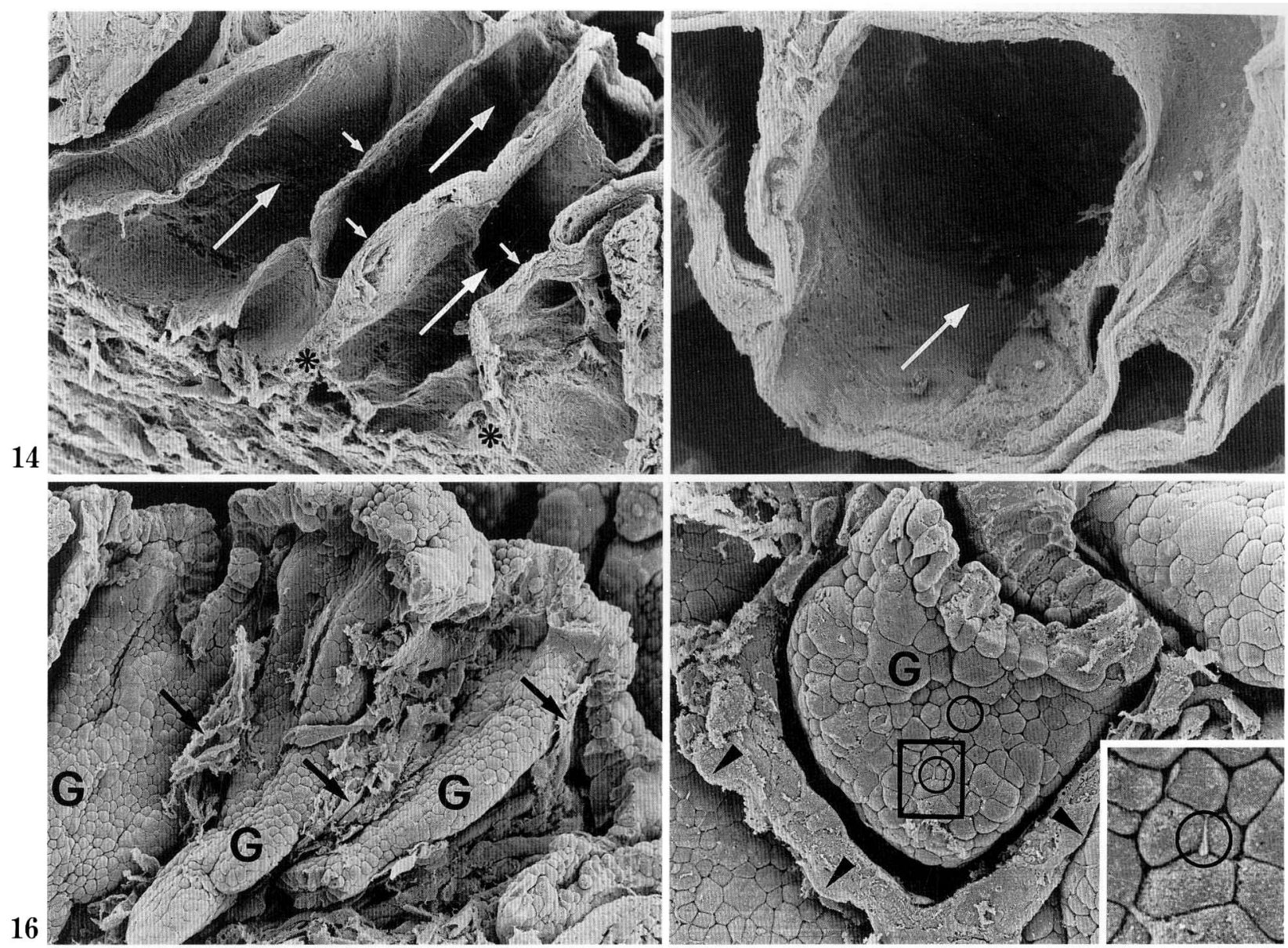

Figs. 14-17. SEM of freeze-cracked specimens from pregnant rabbit endometrium at term after maceration with $2 \mathrm{~N}-\mathrm{NaOH}$ (Figs. 14, 15) and $6 \mathrm{~N}-\mathrm{NaOH}$ (Figs. 16, 17). Figs. 14 and 15. Collagen fibrillar skeleton of the endometrium with many endoluminal projections (short arrows) enclosing deep tunnel-like invaginations (long arrows). Asterisks indicate basal areas of these projections demonstrated at a higher magnification in Figures 12 and 13. Figs. 16 and 17. Endometrial glands $(G)$ surrounded by periglandular capillaries with pericytes (arrowheads) and some stromal cells (arrows). The glands are composed of a monolayer of cylindrical cells as seen from their basal part. Often thin cellular projections connect neighbouring cells (circles). Fig. 14: $\times 180$, Fig. 15: $\times 260$, Fig. $16: \times 220$, Fig. $17: \times 500$, inset $\times 1,500$

usually $100-150 \mu \mathrm{m}$ in width and $200-300 \mu \mathrm{m}$ in length. The walls of these invaginations are about $5-10 \mu \mathrm{m}$ thick and present thin projections towards the uterine cavity. These structures are composed of a continuous and compact layer of fibrils running perpendicular to the cross section of the endometrium and parallel to its longitudinal axis. Therefore, their collagen skeleton is denser than that observed in corresponding structures found in the progestational uterus (Fig. 15). The collagen fibrils of the projections reveal an arrangement similar to that of the network facing the endoluminar surface. No fenestrations or discontinuity in the collagen texture are detected at this level.

Comparative $6 \mathrm{~N}-\mathrm{NaOH}$ digestion of the collagen structures demonstrates that these invaginations are housed by endometrial glands (Figs. 16, 17). The latter are composed of a monolayer of cylindrical cells. When observed from their apical pole, they are characterized by a cobblestone appearance. After removal of the basal lamina and interstitial collagen of the endometrial stroma, the glandular cells are easily accessible and their basal parts are polyhedral in shape. In some cases long, thin cytoplasmic projections interconnect with neighbouring as well as distant cells (Fig. 17). Numerous small blood vessels, 
mainly capillaries, run close to the endometrial glands, following their profiles (Figs. 16, 17). The walls of the capillaries are provided with numerous pericytes (Fig. 17).

\section{DISCUSSION}

The present study reveals the fine details of the 3-D architecture of the endometrial collagen network in pregnancy at term using alkali maceration followed by $\mathrm{LM}$ and SEM observations. Applying $2 \mathrm{~N}-\mathrm{NaOH}$ solution results in the digestion of all cells, basal laminae and ground substance, thus preserving only the collagen structures that remain in situ without alterations. In contrast, $6 \mathrm{~N}-\mathrm{NaOH}$ maceration destroys collagen fibrils preserving cells and other tissue structures such as glands and vessels. Therefore, combining these two techniques makes it possible to obtain additional complementary data on the morphologic features of the endometrium at term and especially its collagen skeleton. Our results demonstrated that the collagen fibrils are organized in a continuous network pervading the whole uterus. In fact, a clear continuity of the collagen network of the endometrium into the myometrium was observed. Thus, although the myometrium and the endometrium represent two different morpho-functional compartments of the uterus, the collagen framework joins them together into a unique structure. These results certainly emphasize the central biomechanical role of this complex fibrillar skeleton-which cannot be fully appreciated with any other method.

In addition, the present data, if compared with our previous observations on the collagen skeleton of the endometrium at estrous, ovulation and progestation (GORANOVA et al., 1993b), show significant changes in its architecture with respect to these phases of the reproductive cycle. The modifications in the spatial arrangement of the endometrial collagen fibrils established at the end of pregnancy reveal some similarities with the changes observed in the progestational phase, though here expressed at a higher degree. In fact, the characteristic aspect of the endometrial luminal surface after maceration with $2 \mathrm{~N}-\mathrm{NaOH}$ in estrous and ovulatory animals showing a rosette-like distribution of its collagen fibrils is completely absent. Instead of this, a disorganized and diffuse arrangement around the extremely deformed glandular orifices was present. Our results on the 3-D collagen organization in the endometrium are consistent with the data by ALPIN (1994) on the morphological and biochemical remodeling of the endometrial stroma during pregnancy. In non-pregnant endome- trium collagen fibrils organized in bundles prevail, whereas the decidual stroma contains mostly single fibrils which run anisotropically through the tissue, this being due to a decrease in the overall concentration of fibrillar collagen (ALPIN, 1994). An important feature observed during pregnancy relates to the presence of numerous imprints of subepithelial capillaries with a "squared" aspect not found in other stages. The holes of the blind endings of the channellike imprints might correspond to sites where capillaries of the subepithelial plexus originate from or terminate into underlying vessels.

Our findings suggest that an evident spatial remodeling of the collagen network takes place also in this phase of the reproductive cycle. Obviously this is due to an increased plical folding and distention of the whole uterus during pregnancy. Furthermore, both LM and SEM observations demonstrate that the collagen fibrillar network of the endometrium during pregnancy (in particular in the cores of the stromal projections) is more compact than in the progestational phase. The intensive epithelial proliferation and secretion typical for the endometrium in this phase (MOTTA and ANDREWs, 1976; BARBERINI et al., 1978) play an important role in the pregnant uterus, further leading to more relevant changes in its 3-D collagen configuration. Lately it has been shown that the collagen structures of the uterus are estrogen dependent, too (RAJABI et al., 1991; PASTORE et al., 1992), as are its cellular components (MCCORMACK and Glasser, 1980; Conti et al., 1984; FinN, 1985; SPORNITZ et al., 1994) and its capillaries (FRIEDERICI, 1967; MARTIN et al., 1973). These data are in agreement with our findings on the occurrence of a massive epithelial proliferation during pregnancy which is obviously estrogen related. The intensive glandular secretion, stimulated by progesterone, further produces specific remodeling in the collagen network of the pregnant uterus.

Finally, our study revealed that the architecture of the endometrial collagen at the end of pregnancy has some similarities with that of the progestational phase, although it is more complex and clearly altered. These data demonstrate that pregnancy affects in a very significant way the 3 -D collagen organization of the endometrium, and this in turn may be required for successful implantation, placentation and delivery.

Acknowledgements. The authors wish to thank Mr. G. FRANCHITTO for his excellent technical assistance. 


\section{REFERENCES}

Alberto-Rincon, M. C., T. M. T. Zorn and P. A. Abrahamsohn: Diameter increase of collagen fibrils of the mouse endometrium during decidualization. Amer. J. Anat. 186: 417-429 (1989).

AlPin, J. D.: Products of endometrial differentiation. In: (ed. by) T. Chard and J. G. GRudzinskas: The uterus. Cambridge University Press, 1994 (p. 125-147).

Amso, N. N., J. Crow, J. Lewin and R. W. Shaw: A comparative morphological and ultrastructural study of endometrial gland and Fallopian tube epithelia at different stages of the menstrual cycle and the menopause. Hum. Reprod. 9: 2234-2241 (1994).

Barberini, F., S. Sartori, P. MotTa and J. VAN Blerkom: Changes in the suface morphology of the rabbit endometrium related to the estrous and progestational stages of the reproductive cycle. A scanning and transmission electron microscopic study. Cell Tiss. Res. 190: 207-222 (1978).

BoREL, J. P.: Les collagènes utérins. Revue générale. Rev. Franc. Gynécol. Obstét. 86: 715-722 (1991).

Clark, D. E., P. R. Hurst, D. B. Myers and G. F. Spears: Collagen concentrations in dissected tissue compartments of rat uterus on days 6,7 and 8 of pregnancy. J. Reprod. Fertil. 94: 169-175 (1992).

Clark, D. E., P. R. Hurst, I. S. Mclennan and D. B. MYERS: Immunolocalization of collagen type I and laminin in the uterus on days 5 to 8 of embryo implantation in the rat. Anat. Rec. 237: 8-20 (1993).

Conti, C. J., I. B. Gimenez-Conti, E. A. Conner, J. M. LEHMAN and L. E. GERSCHENSON : Estrogen and progesterone regulation of proliferation, migration, and loss in different target cells of rabbit uterine epithelium. Endocrinology 114: 345-351 (1984).

Dockery, P. and A. W. Rogers: The effects of steroids on the fine structure of the endometrium. Baillère's Clin. Obstet. Gynaecol. 3: 227-248 (1989).

FEDER, H. H.: Estrus cyclicity in mammals. In: (ed. by) N. T. AdLER: Neuroendocrinolgy of reproduction. Physiology and behavior. Plenum Press, New York-London, 1981 (p. 279-348).

FinN, C. A.: Uterine response to corpus luteum. In: (ed. by) C. Jeffconte: The luteal phase. John Wiley and Sons Ltd., 1985 (p. 43-59).

Friederici, H. H. R.: The early response of uterine capillaries to estrogen stimulation. Lab. Invest. 17: 322333 (1967)

Goranova, V., E. Vizza and P. M. Motta: Threedimensional architecture of the collagen framework and blood vessels in the estrous rabbit uterus. In: (ed. by) Grafiche ZANNINI: Proceedings of the Multinational Congress on Electron Microscopy. Bologna, 1993a (p. 475476).

in - : Collagen fibrillar network in estrous and hCG-stimulated rabbit uterus: A SEM study after $\mathrm{NaOH}$ maceration. Arch. Histol. Cytol. 56: 231-241 (1993b).
JeFFREY, J. J.: Collagen and collagenase: pregnancy and parturition. Semin. Perinatol. 15: 118-126 (1991).

Kaidi, R., P. J. Brown, J. S. David, D. J. Etherington and S. P. Robins: Uterine collagen during involution in cattle. Matrix 11: 101-107 (1991).

Kikuta, A., O. Ohtani and T. Murakami: Three-dimensional organization of the collagen fibrillar framework in the rat adrenal gland. Arch. Histol. Cytol. 54: 133-144 (1991).

Kisalus, L. L., J. C. HerR and C. D. LitTle: Immunolocalization of extracellular matrix proteins and collagen synthesis in first-trimester human decidua. Anat. Rec. 218: 402-415 (1987).

Kramer, B., B. A. Stein and L. A. VAN Der Walt: Exogenous gonadotropins-serum estrogen and progesterone and the effect on endometrial morphology in the rat. J. Anat. 173: 177-186 (1990).

LudwiG, H.: The morphological response of the human endometrium to long term treatment with progestational agents. Amer. J. Obstet. Gynecol. 142: 796-808 (1982).

Martel, D., R. Fryman, M. Glissant, C. Maggioni, D. Roche and A. Psychoyos: Scanning electron microscopy of postovulatory human endometrium in spontaneous cycles and cycles stimulated by hormone treatment. J. Endocrinol. 114: 319-327 (1987).

Martello, E. M. V. G. and P. A. Abrahamsohn: Collagen distribution in the mouse endometrium during decidualization. Acta Anat. 127: 146-150 (1986).

Martin, L., R. C. Hallowes, C. A. Finn and D. G. WEST: Involvement of the uterine blood vessels in the refractory state of the uterine stroma which follows oestrogen stimulation in progesterone treated-mice. J. Endocrinol. 56: 309-314 (1973).

McCormack, S. A. and S. R. Glasser: Differential response of individual uterine cell types from immature rats treated with estradiol. Endocrinology 106: 16341649 (1980).

Minamoto, T., K. Arai, S. Hirakawa and Y. Nagai: Immuohistochemical studies on collagen types in the uterine cervix in pregnant and nonpregnant states. Amer. J. Obstet. Gynecol. 156: 138-144 (1987).

MotTA, P. M. and P. M. AndRews: Scanning electron microscopy of the endometrium during the secretory phase. J. Anat. 122: 315-322 (1976).

Mulholland, J., J. D. Alpin, S. Ayad, L. Hong and S. R. GLAsser: Loss of collagen type VI from rat endometrial stroma during decidualization. Biol. Reprod. 46: 1136-1143 (1992).

Mylona, P., C. M. Kielty, J. A. Hoyland and J. D. ALPIN: Expression of type VI collagen mRNAs in human endometrium during the menstrual cycle and first trimester of pregnancy. J. Reprod. Fertil. 103: 159167 (1995).

Ohtani, 0.: Three-dimensional organization of the connective tissue fibers of the human pancreas: A scanning electron microscopic study of $\mathrm{NaOH}$ treated tissue. Arch. Histol. Jap. 50: 557-566 (1987).

: Three-dimensional organization of the collagen 
fibrillar framework of the human and rat livers. Arch. Histol. Cytol. 51: 473-488 (1988).

: The maceration technique in scanning electron microscopy of collagen fibers frameworks: Its application in the study of human livers. Arch. Histol. Cytol. 55, Suppl.: 225-232 (1992).

Ohtani, 0., T. Ushiki, T. Taguchi and A. Kikuta: Collagen fibrillar network as skeletal frameworks: A demonstration by cell-maceration/scanning electron microscope method. Arch. Histol. Cytol. 51: 249-261 (1988).

Pastore, G. N., L. P. Dicola, N. R. Dollahon and R. M. Gardner: Effect of estriol on the structure and organization of collagen in the lamina propria of the immature rat uterus. Biol. Reprod. 47: 83-91 (1992).

RaJABI, M. R., G. R. Dodge, S. Solomon and A. Robin: Immunochemical and immunohistochemical evidence of estrogen-mediated collagenolysis as a mechanism of cervical dilatation in the guinea pig at parturition. Endocrinology 128: 371-378 (1991).

Spornitz, U. M., B. R. Rinderknecht, A. Edelmann, B. Scheidegger and F. CAIroli: Ultrastructure as a basis for dating of rat endometrium. Anat. Rec. 238: 163-176 (1994).

UldbJerg, N., G. Ekman, A. Malmstöm, K. Olsson and U. Ulmsten: Ripening of the human uterine cervix related to changes in collagen glycosaminoglycans and collagenolytic activity. Amer. J. Obstet. Gynecol. 147: 662-666 (1983).
Vizza, E., U. Muglia, V. Goranova, V. Papagianni and S. CoRRER: The fibromuscular skeleton of the rabbit oviduct. A correlative SEM study with $2 \mathrm{~N}-\mathrm{NaOH}$ maceration. In: (ed. by) Grafiche ZANNINI: Proceedings of the Multinational Congress on Electron Microscopy. Bologna, 1993 (p. 473-475).

Vizza, E., S. Correr, V. Goranova, U. Muglia and P. M. MotTA: Microarchitettura tridimensionale del collagene nell'apparato genitale femminile. Ital. J. Anat. 99: 7 (1994).

Yoshida, Y. and Y. Manabe: Different characteristics of amniotic and cervical collagenous tissue during pregnancy and delivery: A morphologic study. Amer. J. Obstet. Gynecol. 162: 190-193 (1990).

\author{
Dr. Enrico VizzA \\ Department of Anatomy \\ Medical School \\ University of Rome "La Sapienza" \\ via A. Borelli, 50 \\ 00161 Rome, Italy
}

